\title{
DESENCONTROS LEGAIS E MORAIS NA PESCA ARTESANAL: A EdUCAÇÃo ambiental política Para a tranSformaÇão SOCIOAMBIENTAL EM RIO GRANDE/RS E SÃO JOSÉ DO NORTE/RS
}

\begin{tabular}{c}
\hline LEGAL AND MORAL DISAGREEMENTS IN ARTISANAL FISHERY: \\
POLITICAL ENVIRONMENTAL EDUCATION FOR SOCIAL AND ENVIRONMENTAL \\
TRANSFORMATION IN RIO GRANDE/RS AND SÃO JOSÉ DO NORTE/RS \\
\hline DESENCUENTRO LEGALES Y MORAIS EN LA PESCA ARTESANAL: \\
LA EDUCACIÓN AMBIENTAL POLÍTICA PARA LA TRANSFORMACIÓN \\
SOCIOAMBIENTAL EN RIO GRANDE/RS Y SÃO JOSÉ DO NORTE/RS
\end{tabular}

Janaina Agostini Braido ${ }^{1}$ Vanessa Hernandez Caporlingua ${ }^{2}$

\begin{abstract}
RESUMO: Este artigo apresenta a compreensão de pescadores artesanais das cidades de Rio Grande/RS e São José do Norte/RS acerca do desencontro entre as normas legais pesqueiras e as normas morais dos pescadores, e os reflexos na conservação do meio ambiente e no exercício da cidadania ambiental, a fim de colaborar, por intermédio da Educação Ambiental (EA), para a reversão da crise vivenciada na pesca da região, bem como para refletir sobre a ineficiência daquelas leis. O estudo foi feito por meio de levantamento bibliográfico e documental, e aplicação de grupos focais em comunidades pesqueiras. Os resultados indicaram que a EA política possui papel fundamental no empoderamento dos pescadores para sua participação nos processos de gestão na pesca, voltada à conservação ambiental e edificação do bem coletivo. Em considerações finais, sugeriu-se a realização de cursos de EA nas comunidades, o incentivo à participação dos pescadores nas reuniões da categoria e a desburocratização da atividade.
\end{abstract}

PALAVRAS-CHAVE: Educação ambiental. Pesca artesanal. Lei versus moral.

ABSTRACT: This article presents the understanding of the artisanal fishing communities in Rio Grande/RS and São José do Norte/RS about the mismatch between the fishing legal rules and the moral norms of fishermen, and the consequences of this mismatch in environmental conservation and exercise of the environmental citizenship, to collaborate, through Environmental Education (EA), for the reversal of the crisis experienced in fisheries in the region, as well as to reflect on the inefficiency of those rules. The study was conducted through a bibliographic and documentary survey, as well as application of focus groups in fishing communities. The collected results indicated that the political EA has a key role in the empowerment of the fishermen in search of active participation in the management of the fishery resources in real participatory governance focused on environmental conservation and building up of the collective welfare. In final considerations, it was suggested to undertake EA courses in the communities, to encourage the participation of fishermen in the category' meetings and to reduce the bureaucracy of the activity.

KEYWORDS: Environmental education. Artisanal fishery. Law vs. moral.

RESUMEN: Este artículo contiene una comprensión de pescadores artesanales de las ciudades de Rio Grande/RS y São José do Norte/RS, acerca del desencuentro entre las normas legales pesqueras y como las normas morales de los pescadores, y los reflejos en la conservación del medio ambiente y el ejercicio de la ciudadanía. ambiental, a fin de colaborar, por intermedio da Educación Ambiental (EA), para la reversión de la crisis

\footnotetext{
${ }^{1}$ Submetido em: 02/04/2018 - Aceito em: 16/04/2018 - Publicado em: 31/12/2018
}

\begin{tabular}{l|l|l|l|l|l|l} 
(C) Rev. Educ. Perspec. & Viçosa, $M G$ & v.9 & n.2 & p. 347-363 & maio/ago. 2018 & eISSN 2178-8359 \\
\hline
\end{tabular}


vivenciada en la pesca de la región, así como para reflexionar sobre la ineficacia de las reglas. El estudio fue realizado por medio de levantamiento bibliográfico y documental, así como aplicación de grupos focales en las comunidades pesqueras. Los resultados indicaron que la Educación Ambiental política tiene un papel fundamental para el empoderamiento de los pescadores artesanales en busca de su participación en los procesos de gestión en la pesca. En consideraciones finales, se sugirió la realización de cursos de EA en las comunidades, incentivar la participación de los pescadores en las reuniones de la categoría y la desburocratización de la actividad.

PALABRAS CLAVE: Educación ambiental. Pesca artesanal. Ley versus moral.

\section{INTRODUÇÃO}

Este artigo se constituiu a partir de uma pesquisa de mestrado, realizada com pescadores artesanais do sul do estuário da Lagoa dos Patos, nas cidades do Rio Grande e de São José do Norte, no estado do Rio Grande do Sul (RS). O trabalho teve como propósito perceber a compreensão das comunidades tradicionais acerca do desencontro entre os instrumentos legais aplicáveis à pesca e suas normas morais, e como a Educação Ambiental, entendida como educação política, pode promover a transformação socioambiental a partir da realidade cultural e econômica dos sujeitos pesquisados.

A pesca é uma das atividades extrativistas mais antigas que se tem conhecimento no mundo, e uma importante fonte de alimentos desde as sociedades primitivas. No Brasil, os primeiros registros dessa arte como forma de exploração econômica datam do início do século XX, em decorrência da falência na economia dos ciclos do açúcar e do café (DIEGUES, 1983). Já a partir de 1960, a pesca sofreu uma significativa transformação por meio dos incentivos governamentais concedidos ao setor industrial. O crescimento da frota e a aquisição de equipamentos e petrechos modernos propiciaram o aumento das capturas, principalmente na costa. O consequente declínio dos estoques foi sentido pela pesca artesanal, resultando na necessidade de intensificação do esforço da pesca e na pesca predatória.

Numa tentativa de minimizar os riscos de tais fatores exploratórios, um novo ordenamento ambiental passou a disciplinar as atividades relacionadas aos meios extrativistas, principalmente após a década de 1980, com a definição de períodos de defeso, controle de petrechos e técnicas, limitação de tamanho das espécies a serem capturadas entre outras.

Nesse contexto, algumas práticas tradicionais de autogestão dos recursos na pesca artesanal, passadas de geração em geração, além de outras introduzidas pelos naturais processos de adaptação e evolução da atividade, restaram impedidas e/ou restringidas pela nova legislação. $\mathrm{O}$ consequente desencontro entre as normas morais dos pescadores e aspectos das regras legais, criadas sem a oportunidade de diálogo e do compartilhamento de conhecimentos, passou a gerar diversos conflitos entre aqueles e a fiscalização ambiental, com a falta de

\begin{tabular}{l|l|l|l|l|l|l} 
(c) Rev. Educ. Perspec. & Viçosa, $M G$ & v.9 & n.2 & p. 347-363 & maio/ago. 2018 & eISSN 2178-8359 \\
\hline
\end{tabular}


efetividade (ausência de observância da norma jurídica pelos destinatários) de algumas normas e o desrespeito à legislação ambiental vigente.

Considerando o cenário exposto, a fim de colaborar com o fortalecimento dos pescadores, por intermédio da Educação Ambiental, para a reversão do quadro de crise socioambiental vivenciada na pesca artesanal no estuário da Lagoa dos Patos, o trabalho foi desenvolvido mediante a utilização de uma metodologia que privilegiou a pesquisa qualitativa de dados.

O primeiro momento se constituiu em uma pesquisa bibliográfica e documental sob a temática da Educação Ambiental, do Direito e da Sociologia, voltadas à atividade pesqueira, e envolveu a coleta dos dados pertinentes aos possíveis aspectos do distanciamento entre as normas legais ambientais e as normas morais dos pescadores tradicionais das cidades pesquisadas. No segundo momento, foram investigados os reflexos dos aspectos do desencontro mencionado no declínio da conservação dos recursos pesqueiros e no exercício da cidadania pelos pescadores. Para tanto, foram realizados grupos focais com os pescadores de quatro localidades, com a introdução de temáticas pertinentes ao trabalho.

O método do grupo focal foi escolhido por propiciar a compreensão dos diferentes fenômenos sociais dos pescadores estudados, a partir de uma perspectiva coletiva. Para a obtenção desses fenômenos, optou-se pela análise das representações coletivas de Émile Durkheim, as quais, forjadas no cotidiano das interações sociais, são funções mentais que sintetizam o pensamento de determinado grupo em suas relações com os objetos que o afetam, ou seja, o que pensa sobre si e sobre a realidade que o cerca (DURKHEIM, 2007).

Posteriormente, mediante a utilização da ferramenta Análise Textual Discursiva (MORAES; GALIAZZI, 2007), foram delineadas as categorizações emergentes dos discursos e representações dos sujeitos participantes, as quais foram analisadas em conjunto com a pesquisa bibliográfica e documental, formando-se o corpus de análise da pesquisa.

\section{A ATIVIDADE PESQUEIRA ARTESANAL EM RIO GRANDE/RS E SÃO JOSÉ DO NORTE/RS}

No Brasil, a atividade pesqueira artesanal é desenvolvida tanto no litoral quanto em águas interiores, e praticada por pescadores autônomos que a exercem de forma individual, em regime de economia familiar ou em parceria. A captura é realizada com petrechos e equipamentos mais simples quando comparados à pesca industrial, variando em função das espécies, e com a utilização ou não de embarcações de pequeno/médio porte.

Nas cidades do Rio Grande/RS e de São José do Norte/RS, a pesca artesanal é desenvolvida no interior do estuário da Lagoa dos Patos e na costa. Esses municípios possuem uma longa

\begin{tabular}{l|c|c|c|c|c|c} 
(C) Rev. Educ. Perspec. & Viçosa, $M G$ & v.9 & n.2 & p. 347-363 & maio/ago. 2018 & eISSN 2178-8359 \\
\hline
\end{tabular}


ligação natural e histórica, apesar de apresentarem realidades socioeconômicas distintas, estando divididos pelo canal que une o estuário ao Oceano Atlântico (figuras 1 e 2).

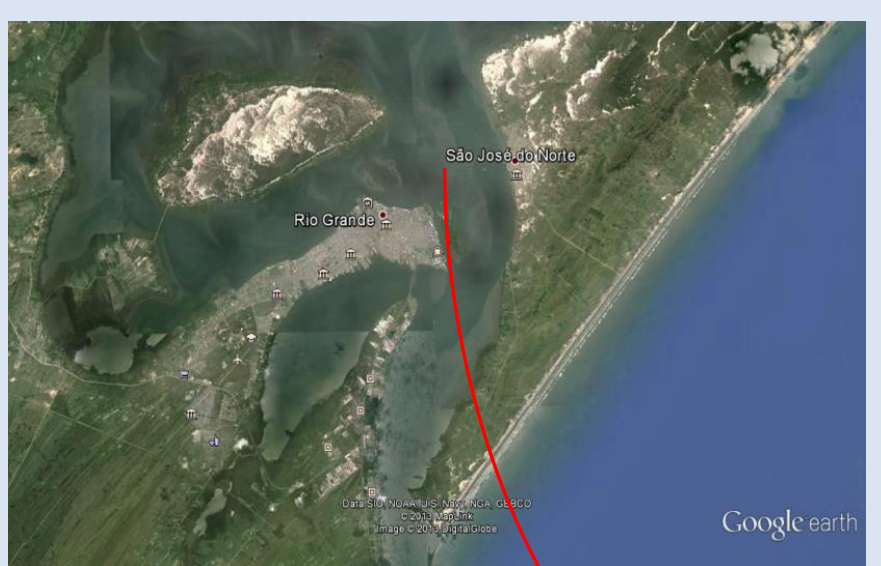

Figura 1. Municípios do Rio Grande e de São José do Norte. Fonte: Google Earth-mapas. Acesso em: 24 nov. 2013.

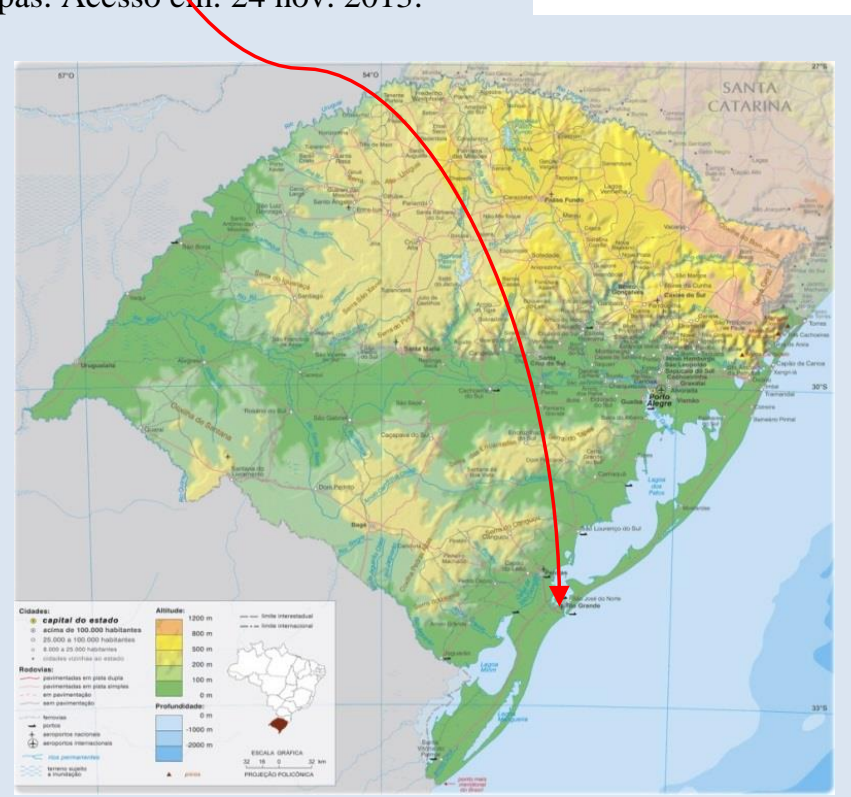

Figura 2. Mapa do estado do RS.

Fonte: Site Mapas. Disponível em: 〈www.mapas-rs.com>. Acesso em: 24 nov. 2013.

A Lagoa dos Patos, classificada como a maior lagoa (sic) do tipo "estrangulado" no mundo, conta com uma superfície de $10.227 \mathrm{~km}^{2}$, e uma área estuarina de $971 \mathrm{~km}^{2}$ (ASMUS, 1998). Rico em biodiversidade, o ambiente estuarino proporciona aos moradores do entorno da região urbana e da zona rural do Rio Grande e de São José do Norte uma relação muito próxima com a pesca artesanal, atividade praticada no estado desde o período de colonização.

A atividade artesanal pode ser dividida com base nos recursos disponíveis para o seu exercício. Os pescadores que trabalham na captura, podem ser classificados como os que 
atuam embarcados e os que permanecem nas margens do estuário. Os primeiros são proprietários dos bens de produção ou proeiros que participam com sua força de trabalho. A distribuição da produção é feita pelo sistema de cotas ou partes, cabendo geralmente ao proprietário a metade do total líquido. Os pescadores desembarcados, por sua vez, trabalham individualmente ou em dupla, praticando, em geral, a pesca de subsistência. O camarão-rosa representa a principal fonte de renda para os pescadores, e as outras pescarias, que tradicionalmente forneciam rendimento no decorrer do ano, estão em declínio em razão da pesca predatória, degradação ambiental, dentre outros fatores.

Como forma de proteção das espécies durante as fases mais críticas de seus ciclos de vida, a Instrução Normativa Conjunta MPA/SEAP 03/2004 ${ }^{\mathrm{i}}$ estabeleceu paralisações temporárias da pesca em determinados períodos no ambiente estuarino, conforme cada pescaria. Popularmente conhecida como defeso, essa paralisação foi criada para favorecer a conservação dos estoques pesqueiros, evitando a captura em períodos nos quais os peixes e os crustáceos estão mais vulneráveis por se encontrarem reunidos em cardumes, como quando da reprodução.

A comercialização do pescado, por outro lado, é diversificada conforme o distanciamento do local de captura em relação aos centros urbanos, o grau de organização dos pescadores e a sua capacidade financeira. A maior parte do produto costuma ser repassado in natura a atravessadores, devido à carência de infraestrutura para o seu processamento e beneficiamento. $\mathrm{O}$ ingresso dessa figura na cadeia produtiva atua não apenas na aquisição do pescado, mas também como fornecedor de materiais e financiador nas entressafras, vinculando aquele profissional e criando uma relação de dependência econômica.

Diversos são os fatores que refletem a precária situação socioeconômica das comunidades tradicionais de pescadores, tais como a reduzida escolaridade; deficientes condições de acesso à saúde, saneamento e moradia; ineficiente representatividade enquanto categoria profissional; e carência na infraestrutura para o trabalho. Essas dificuldades foram acentuadas pela diminuição da disponibilidade dos estoques devido à pesca predatória, à sobrepesca, à degradação ambiental, à poluição e às condições climáticas desfavoráveis (REIS et al., 2011).

Enquanto categoria profissional, os pescadores são representados pelas colônias de pesca. As primeiras colônias de pescadores do Brasil foram fundadas em 1919, objetivando prioritariamente organizar as comunidades para a defesa da costa brasileira como segmento de reserva da Marinha do Brasil (KALIKOSKI; VASCONCELLOS, 2012; DIEGUES, 1983). Quando da fundação, as colônias estiveram sob o controle e a dominação política de órgãos governamentais. Com o advento da Constituição Federal de 1988, os pescadores artesanais conquistaram novos direitos sociais e políticos, principalmente após a equiparação das colônias aos sindicatos de trabalhadores rurais, recebendo uma configuração sindical.

\begin{tabular}{l|l|l|l|l|l|l} 
(C) Rev. Educ. Perspec. & Viçosa, $M G$ & v.9 & n.2 & p. 347-363 & maio/ago. 2018 & eISSN 2178-8359 \\
\hline
\end{tabular}


A parca representatividade das colônias frente aos pescadores é lembrada por Diegues (1983), cuja maioria limita-se à distribuição de carteiras de pescadores e a atividades sociais marcadas por um alto grau de paternalismo, como na distribuição de remédios, serviços dentários etc. $\mathrm{O}$ mesmo autor destaca que os presidentes, normalmente pertencentes a uma facção política governamental, controla por meio dessas atividades os votos dos pescadores em época de eleição.

Além das colônias, diversos grupos sociais organizados possuem relação com a pesca artesanal, a exemplo do Fórum da Lagoa dos Patos, organização não governamental de cooperação no âmbito pesqueiro, criada em 1996 com o objetivo de contornar a crise do setor pesqueiro artesanal, decorrente da crescente queda da produtividade extrativista, mediante a criação de alternativas de manejo dos recursos naturais. O Fórum abrange os municípios de Rio Grande, São José do Norte, São Lourenço do Sul e Pelotas, e reúne instituições de governo, entidades da sociedade civil organizada, organizações classistas e pescadores (FÓRUM DA LAGOA DOS PATOS, 1998).

A criação dessa organização representou à época uma tentativa de cogerenciamento da pesca artesanal na região, com o compartilhamento dos saberes tradicionais. Entretanto, a devolução do poder às comunidades pesqueiras foi dificultada pela pouca participação dos pescadores no Fórum, e também por influências externas em diferentes níveis de governo (KALIKOSKI, 2002). Ademais, a pobreza e o difícil acesso às ações de cidadania tornaram os pescadores alvos fáceis para oportunistas. Apesar das atividades do Fórum, constata-se que tal situação tem se agravado nos últimos anos, com o distanciamento da população mais carente das reuniões e pela insuficiente representatividade das lideranças (PEREIRA, 2006).

Essa reduzida participação cidadã dos pescadores nas esferas de decisão de sua vida social e política acabou por conduzir ao desencontro entre aspectos das normas legais pesqueiras e as normas morais dos pescadores artesanais da região, e consequentemente à falta de efetividade da legislação ambiental aplicável ao ambiente estuarino.

\section{APROXIMAÇÕES E DISTANCIAMENTOS ENTRE O DIREITO E A MORAL E OS REFLEXOS DO DESENCONTRO ENTRE ASPECTOS DAS NORMAS LEGAIS E MORAIS NA PESCA ARTESANAL}

O Direito está presente nas mais diferentes sociedades desde a pré-história da humanidade, período em que suas fontes normativas eram constituídas basicamente pelos costumes e pelas tradições. Na evolução jurídica traçada por muitos povos, o Direito foi se adaptando à realidade e à necessidade de cada grupo, sendo essencial para o convívio dos indivíduos. 
Na língua portuguesa, o termo direito deriva do latim directum, correspondendo à ideia de regra, de direção, diferentemente dos romanos, que o denominavam jus, porém não no sentido de justiça, mas de qualidade do Direito (GUSMÃO, 2008). O entendimento vulgar do Direito, porém, não parte necessariamente de um sentido puro de justiça, representando por vezes situações entendidas como opostas à conduta social esperada pelos indivíduos. Segundo Ferraz Júnior (2003), o Direito aparece aos leigos como um complicado mundo de contradições e coerências, uma vez que em seu nome tanto se veem respaldadas as crenças em uma sociedade ordenada quanto se agitam a revolução e a desordem.

As divergências que envolvem o Direito, entretanto, não estão adstritas aos seus sentidos, abrangendo também as definições apresentadas pela doutrina. De fato, a unicidade de sua conceituação é muito difícil, podendo ser entendido enquanto sistema de normas jurídicas, objetivando regular as relações sociais e a atender ao interesse geral (direito objetivo); como a faculdade concedida aos indivíduos de acionar a ordem jurídica a favor de seus interesses, invocando o cumprimento de normas jurídicas existentes (direito subjetivo); e, finalmente, como ciência autônoma que tem o Direito como seu objeto de estudo.

Relacionada ao direito objetivo, a norma jurídica é a proposição normativa inserida em uma fórmula jurídica, garantida pelo poder público ou pelas organizações internacionais, visando preservar a ordem e a paz social e internacional (GUSMÃO, 2008). Conforme Lyra Filho (1982), as normas jurídicas apresentam como características a heteronomia, a bilateralidadeatributiva e a coercibilidade. A primeira refere-se à sujeição dos indivíduos à vontade de quem têm o poder de regular condutas; a segunda, à relação na qual um dos sujeitos é investido no direito subjetivo de reclamar o que a própria norma (direito objetivo) lhe garante, impondo-se a outro sujeito o dever de respeitar; e, por fim, à definição de uma sanção organizada, ou seja, quando a norma tem órgão e processo exatamente definidos para a sua aplicação.

A moral, por sua vez, consiste em um conjunto de regras, princípios e valores que determinam a conduta dos indivíduos em sociedade. Tem origem nas tradições e nas obrigações sociais que disciplinam o comportamento de cada pessoa, atuando de uma forma interna e diferenciando-se de indivíduo para indivíduo, ou de sociedade para sociedade. A norma moral apresenta certa coercibilidade em determinados grupos sociais, nos quais a forma do conhecimento encontra-se à mercê do senso comum e sua inobservância ou transgressão acarreta sanções morais eventualmente mais severas do que as legais existentes. Para Durkheim (2004), cada povo, cada grupo, em um determinado momento de sua história, possui uma moral reinante.

Ocorre que muitos conflitos verificados na sociedade advêm do fato de o conteúdo da norma jurídica não refletir aspectos dos ditames da moral coletiva. A vigência das normas, por si só, não conduz a uma obediência feudal e necessariamente espontânea por parte dos indivíduos.

\begin{tabular}{l|l|l|l|l|l|l} 
(C) Rev. Educ. Perspec. & Viçosa, $M G$ & v.9 & n.2 & p. 347-363 & maio/ago. 2018 & eISSN 2178-8359 \\
\hline
\end{tabular}


A norma jurídica deve, portanto, harmonizar-se, dentro do possível, com o conjunto de valores coletivos como meio de proteger valores morais substanciais, sob pena de sua observância resultar sem efetividade por parte dos seus destinatários.

Assim, o desencontro entre as normas legais ambientais, de alcance geral (nacional ou regional), e a norma moral coletiva, variável por comunidade ou sociedade, torna-se algo periclitante, com consequências na conservação dos recursos naturais. A norma moral, no caso estudado, insere uma ideia coletiva de aceitabilidade de diversas práticas extrativistas pesqueiras, mesmo que revestidas de irregularidade ou até mesmo de ilegalidade.

No âmbito do estuário da Lagoa dos Patos, o decréscimo da produtividade pesqueira ensejou a publicação de uma série de instrumentos normativos que passaram a impor restrições e limitações relativas à pesca, principalmente após os anos 1980. Muitas dessas regras restringiram os calendários de pesca; ampliaram a proibição de determinados petrechos, tais como o tipo de técnica, tamanho, quantidade e qualidade; e delimitaram os locais permitidos para a captura, dentre outras medidas.

O Fórum da Lagoa dos Patos, nessa perspectiva, exerceu à época da formulação da Instrução Normativa Conjunta MPA/SEAP 03/2004, principal instrumento legal que regula a atividade pesqueira no estuário, uma tentativa de promoção de discussões relevantes no âmbito da administração pesqueira, com a proposição de uma legislação regional específica para o ecossistema estuarino, não obstante as críticas à inexistência da participação efetiva dos pescadores artesanais nesse processo.

Essa reduzida participação dos principais interessados na gestão dos recursos foi percebida quando da não efetividade de muitas das normas ambientais que regulamentam a pesca, por terem sido coercitivamente incorporadas à atividade profissional, contrariando, em muitos aspectos, às práticas e às regras morais coletivas consagradas pelos grupos sociais tradicionais. As divergências resultantes da aplicação de regras estabelecidas sem o compartilhamento entre o conhecimento técnico e o empírico tradicional dos pescadores passaram a ser recorrentes, com crescentes conflitos quando das fiscalizações ambientais.

Esse distanciamento revela a importância da implementação de medidas que possibilitem o exercício da cidadania ambiental pelos pescadores junto às esferas institucionais reguladoras de sua atividade. Essa cidadania envolve ações de efetiva participação e de mobilização dos indivíduos na busca de soluções para os problemas da relação entre as pessoas e o ambiente, ou na prevenção de possíveis riscos ambientais a partir de comportamentos ecologicamente desequilibrados (HIGUSHI; AZEVEDO, 2004). Porém, a cidadania ambiental democrática necessita ser mais do que um instituto meramente legal, devendo tornar-se o elemento central de uma cultura política compartilhada. Uma sociedade multicultural só pode manter-se unida

\begin{tabular}{l|l|l|l|l|l|l} 
(C) Rev. Educ. Perspec. & Viçosa, $M G$ & v.9 & n.2 & p. 347-363 & maio/ago. 2018 & eISSN 2178-8359 \\
\hline
\end{tabular}


se a cidadania não se limitar à visão dos direitos políticos, devendo expandir-se para abranger os direitos culturais e sociais (VIEIRA; BREDARIOL, 1998).

Nesse sentido, a cidadania ambiental revela-se como um legado da Educação Ambiental ${ }^{\mathrm{ii}}$, ao buscar um envolvimento ativo e efetivo do ser humano com a natureza da qual faz parte, na construção de novos padrões socioambientais, e com base na capacitação para a participação dos indivíduos nos espaços relativos à sua vida social e profissional, voltados à edificação do bem coletivo. Entendida como educação política por Reigota (2009), essa Educação Ambiental reivindica e prepara os cidadãos para exigir e construir uma sociedade com cidadania, autogestão e ética nas relações sociais e com a natureza. Nas palavras do autor:

\footnotetext{
Quando afirmamos e definimos a educação ambiental como educação política, estamos afirmando que o que deve ser considerado prioritariamente na educação ambiental é a análise das relações políticas, econômicas, sociais e culturais entre a humanidade e a natureza e as relações entre os seres humanos, visando a superação dos mecanismos de controle e de dominação que impedem a participação livre, consciente e democrática de todos (REIGOTA, 2009, p. 13).
}

Pelo exposto, a Educação Ambiental deve focar justamente a conquista do participar para escolher, do escolher para decidir e do decidir para poder (empoderar). Contudo, segundo Caporlingua (2012, p. 129), "não basta refletir e ter vontade; é essencial agir, por isso a ação política conjunta, dos representantes do governo e dos seus administrados, possibilita maior efetividade dos resultados". Essas lutas populares, para Carvalho (2011, p. 168-169), "podem ser elementos-chave na construção da cidadania ambiental, estabelecendo um campo de diálogo entre as reivindicações ambientais e as demandas populares”.

O fortalecimento e o empoderamento ${ }^{\mathrm{iii}}$ dos pescadores, enfim, visando a um maior engajamento nas decisões políticas, ocorre por meio de sua transformação socioambiental. Tal transformação, entretanto, não deve objetivar alterar os costumes, valores e tradições das comunidades tradicionais, mas mudar a forma como os pescadores são incluídos nas esferas de poder, passando de meros espectadores - quando o são - a efetivos protagonistas, capazes de fazer com que seus conhecimentos e posicionamentos sejam ouvidos, percebidos e, principalmente, verdadeiramente considerados.

\section{Desencontros na legislação pesqueira: uma compreensão para além da moral}

Neste item são apresentados os aspectos do distanciamento entre as leis e as práticas pesqueiras de quatro comunidades da região (Ilha da Torotama e São Miguel em Rio Grande, e Pontal da Barra e Várzea em São José do Norte), e os abalos morais sofridos pelos pescadores nas fiscalizações dos órgãos ambientais.

A partir da análise de suas representações coletivas, ficou evidenciado, com pequenas variações entre os grupos, que a crise instaurada na pesca ultrapassa a questão do desencontro

\begin{tabular}{l|c|c|c|c|c|c} 
() Rev. Educ. Perspec. & Viçosa, $M G$ & v.9 & n.2 & p. 347-363 & maio/ago. 2018 & eISSN 2178-8359 \\
\hline
\end{tabular}


entre as normas legais e morais dos pescadores. Deste modo, além do desencontro mencionado, representado pela tradição ${ }^{\text {iv }}$, pelo conhecimento tradicional e pelo desconhecimento ou incompreensão das normas aplicáveis à atividade, restou detectado outro aspecto ensejador do descumprimento das regras ambientais, qual seja, a dificuldade financeira dos pescadores e de suas famílias.

Importante destacar que o descumprimento das regras ambientais não apresentou entre as comunidades pesquisadas uma classificação estanque. Nesse sentido, uma determinada prática podia ser apontada por um grupo como decorrente da tradição, e justificada pela dificuldade financeira por outro. Ademais, uma mesma localidade podia destacar certo comportamento como resultante da tradição e, ao mesmo tempo, do conhecimento tradicional e/ou da dificuldade, um complementando o outro.

Os aspectos que mais se destacaram nos grupos focais foram a tradição e o conhecimento tradicional, os quais se relacionam com as normas morais das comunidades pesqueiras artesanais, isto é, referem-se à representações de práticas entendidas como corretas pelos pescadores. Tais normas inserem uma ideia coletiva de aceitabilidade de diversas práticas extrativistas pesqueiras, mesmo que revestidas de infrações administrativas ou até mesmo criminais. Elas constituem um imperativo social criado, desenvolvido e modificado, pouco a pouco, em cada comunidade ou sociedade (DURKHEIM, 1983).

No que se refere especificamente à tradição, os pescadores relataram uma série de normas legais que não eram observadas por contrariarem valores morais entendidos como corretos. Percebeu-se que esses valores diziam respeito a comportamentos tradicionais - o que incluía o uso de artes, petrechos, equipamentos, territórios, que lhes foram ensinados ainda quando jovens por seus pais, familiares, vizinhos e/ou amigos, denotando um caráter mais estável dessas representações, assim como entendido por Durkheim (2004). O conhecimento tradicional na pesca, por sua vez, expressaria todo um conjunto de ações e valores carregados da experiência conquistada e repassada de forma geracional, formador das regras morais de cada comunidade.

De outra parte, o desconhecimento ou incompreensão das normas legais foram aspectos que emergiram dos grupos da Torotama, Pontal e Várzea, como formas de representação da crise instaurada na pesca, que acabam ensejando o seu descumprimento. Segundo as reclamações apresentadas, a carência de informações é um grande problema na atividade, situação dificultada pela origem simples dos pescadores artesanais, com reduzido estudo e quase nenhuma inserção política. Ademais, a dificuldade de compreensão da linguagem da legislação também seria problema para os pescadores, que reiteraram a carência de informações e de esclarecimentos pelos órgãos públicos. 
Finalmente, o aspecto da dificuldade financeira, que emergiu de todos os grupos focais, foi apontado como resultado de uma série de problemas que envolve a atividade pesqueira artesanal, a exemplo da diminuição generalizada das capturas, da quebra de safras importantes, do aumento das autuações ambientais e das apreensões, e da crise econômica que atinge diversos setores no país.

Assim, apesar de não se tratar de mais um aspecto do binômio legalidade versus moralidade, nos termos anteriormente desenvolvidos, o fator da dificuldade financeira carrega uma carga moral traduzida em questões elementares de luta e de sobrevivência por muitas comunidades tradicionais, que sobrevivem de uma profissão que, apesar de lhes ser prezada, insere-os em um sistema de pressões emanadas de diversas origens e interesses, tais como políticos, órgãos estatais, setor pesqueiro industrial e atravessadores.

Convém destacar por fim, ainda analisando os problemas enfrentados pelos pescadores quanto à legislação ambiental, os relatos de abusos cometidos nas fiscalizações e outras formas de abalo moral. Tais situações, depreendidas dos discursos de todos os grupos, conduziram a um estigma que paira sobre o setor, principalmente em relação àqueles profissionais cujas práticas são consideradas ilegais pelo ordenamento jurídico.

Segundo Moura (2013), houve uma clara intenção de intimidar as comunidades de pesca e forçá-las ao cumprimento da legislação por meio de diversos abusos de autoridade cometidos pelas instituições de fiscalização, a exemplo de violência verbal e física, aplicação de advertência a ações não enquadradas em lei, abordagens truculentas, humilhação, confisco de redes não ilegais e vistorias sem mandado judicial.

Os grupos dos bairros São Miguel, Pontal e Várzea, em uma construção muito semelhante sobre o modo como os pescadores são vistos pelas instituições públicas, afirmaram existir uma comparação negativa entre a pesca considerada ilegal e crimes graves reprimidos socialmente. Mediante a utilização de palavras e expressões estigmatizantes, já internalizadas em seus discursos, como "ladrão no mar", "nós temo roubando", "nós semo vagabundo", "bandido", "traficante", os participantes afirmaram que algumas práticas não são compreendidas em sua dimensão criminal pelos pescadores, as quais, apesar de contrárias às normas legais, não são reprovadas moralmente por esses atores sociais.

Todos os aspectos dos desencontros na legislação pesqueira, desenvolvidos ao longo deste item, são a seguir tramados com outros problemas que envolvem a pesca na Lagoa dos Patos, e o papel da Educação Ambiental na busca da transformação socioambiental. 
Ações estatais e desencontros legais na pesca artesanal: o papel da Educação Ambiental política para a transformação socioambiental

Quando da realização dos grupos focais nas comunidades pesquisadas, o entendimento sobre a importância da cidadania foi o ponto focal de discussão, porém observou-se uma confusão sobre a concepção dessa representação. Os participantes da Torotama não desenvolveram uma compreensão clara sobre o sentido de cidadania, ao contrário dos pescadores da Várzea, que ora a relacionaram a uma ideia de harmonia entre as pessoas, ora com $\mathrm{o}$ caráter/personalidade de cada um.

Os participantes do bairro São Miguel, por outro lado, construíram uma imagem de cidadania ligada à participação nas esferas de interesses da categoria, bem como ao desejo de comunicar sua vontade, de expressar seus desejos e aflições. Falaram na importância da bagagem advinda da participação contínua dos pescadores, e que, independentemente da escolaridade, algo de relevante é sempre aprendido.

De uma forma geral, os pescadores consideraram importante a participação da categoria em reuniões relacionadas à atividade, porém apresentaram uma série de obstáculos ao exercício de sua cidadania ambiental, tais como o descrédito nos resultados (ou ausência de), nas autoridades e nos representantes; a falta de informações e de convite para as reuniões; a escolha de locais inapropriados para a ampla participação; e a existência de barreiras diversas à comunicação, ligadas à reduzida escolaridade dos pescadores.

Os participantes também demonstram claramente seu descrédito no Fórum da Lagoa. Mencionaram acreditar que as decisões são tomadas pelas autoridades antes mesmo das reuniões, e que as discussões não passam de um engodo para ludibriar os pescadores, passando a falsa ideia de participação. O desejo de união dos pescadores, enfim, foi ressaltado na comunidade da Torotama, que aduziu a necessidade de envolvimento de toda a comunidade. Entretanto, o descrédito e a falta de esperança demonstraram ser verdadeiras barreiras para o exercício da cidadania pelos pescadores artesanais.

Ainda, a falta de confiança nas autoridades e nos representantes da categoria demonstrou ser outra barreira ao exercício da cidadania. Os participantes asseveraram a existência de politicagem nas reuniões da categoria, e a sensação de serem massa de manobra nesses espaços. Há um ressentimento muito grande do jogo político que existe no meio. Quanto às colônias de pesca, os participantes dos bairros São Miguel e Várzea afirmaram que essas entidades aparentam ser mais políticas do que representativas, e que os presidentes e demais integrantes da diretoria possuem interesses políticos, almejando projeção junto aos pescadores como forma de arregimentar eleitores. Foi mencionado por todas as comunidades pesquisadas que as colônias trabalham mais em questões burocráticas na pesca, auxiliando os

\begin{tabular}{l|c|c|c|c|c|c|} 
(C) Rev. Educ. Perspec. & Viçosa, $M G$ & v.9 & n.2 & p. 347-363 & maio/ago. 2018 & eISSN 2178-8359 \\
\hline
\end{tabular}


pescadores na obtenção dos registros e documentos necessários para o exercício da atividade e outros fins correlatos, como benefícios previdenciários.

No que se refere à documentação na pesca, os participantes reclamaram das exigências burocráticas, as quais, não obstante todas as dificuldades inerentes à atividade, extrapolam a condição sociocultural dos pescadores e limitam ainda mais o exercício da cidadania. Tais dificuldades dizem respeito à obtenção dos documentos necessários ao exercício regular da atividade e à multiplicidade de órgãos que gerenciam a pesca.

Por outro lado, constatou-se no decorrer dos diálogos uma aproximação entre as compreensões de cidadania e Educação Ambiental. As primeiras representações sobre Educação Ambiental, entretanto, relacionaram-se à importância da conscientização dos pescadores com a conservação do meio ambiente para as atuais e as futuras gerações. Não se verificou, nessa abordagem inaugural, uma visão mais crítica ao sistema e à gestão da pesca, mas às atitudes dos próprios pescadores.

Os participantes dos bairros São Miguel e Pontal mencionaram que a cidadania exigiria o diálogo entre todos, cada qual sabendo o momento de ouvir e de falar, com a participação das famílias e das mulheres nas reuniões da categoria. Para os mesmos grupos, a oportunidade de diálogo proporcionaria uma maior fiscalização entre os próprios pescadores e os atravessadores, que também necessitariam ser educados ambientalmente.

Conforme depreendido dos discursos, a Educação Ambiental surge como um processo possível voltado para o empoderamento da categoria, no sentido de capacitar os pescadores para participar das decisões que afetam a sua vida (BERKES et al., 2006), sendo condição sine qua non o diálogo entre conhecimentos, gerações e culturas em busca da cidadania brasileira e planetária (REIGOTA, 2009).

A Educação Ambiental, enfim, foi ainda representada em um viés mais analítico, desvelando uma crítica às relações de dominação na sociedade. A partir da análise dos discursos, foi possível compreender a necessidade de os representantes dos órgãos estatais agirem no cumprimento de suas funções institucionais sempre pautados pela dignidade dos cidadãos. Assim sendo, as fiscalizações devem unir seus propósitos institucionais a um caráter preventivo, por meio da conscientização mútua, entendida aqui como a oportunidade de fiscais e fiscalizados compreenderem as dificuldades, as necessidades, os anseios e os propósitos de ambos os lados, e perceberam a imprescindibilidade de conjugar, dentro do possível e do justo, as ideias de conservação do meio ambiente, respeito às tradições e valores, bom senso e cidadania ambiental, ou seja, uma Educação Ambiental compartilhada voltada para o bem comum. 


\section{CONCLUSÕES}

Da análise de todo o corpus de pesquisa, conclui-se que o desencontro entre aspectos das normas legais aplicáveis à pesca no estuário da Lagoa dos Patos, e as normas morais dos pescadores artesanais, além da questão pertinente à dificuldade financeira, apresentaram reflexos negativos no declínio da conservação dos recursos naturais, na medida em que geraram a falta de efetividade de leis relacionadas àquela atividade profissional. A aproximação entre os aspectos relatados neste trabalho e a legislação ambiental mostra-se necessária para o atingimento de normas legais mais efetivas, tendo-se em mente que tanto o meio ambiente natural como o social estão constantemente conectados, devendo ambos ser respeitados e considerados em todas as decisões humanas.

No mesmo sentido, percebeu-se que a falta de efetividade das leis ambientais repercutiu negativamente no exercício da cidadania pelos pescadores artesanais. Com efeito, a imposição de regras de conduta pelo Estado, sem a participação de seus destinatários, desenvolveu entre os pescadores sentimentos de descrédito e desconfiança em todo o sistema, e um consequente desinteresse da categoria no exercício de sua cidadania ambiental.

Nesse diapasão, e analisando as representações coletivas, os diálogos e os relatos dos participantes dos grupos focais, exsurgiram as seguintes possibilidades que poderão auxiliar para a transformação socioambiental daqueles atores sociais:

- Realização de cursos de Educação Ambiental voltados às comunidades tradicionais de pesca, incluindo a participação de servidores públicos e de representantes das colônias de pesca, buscando a troca de saberes e a implementação de orientações sobre cidadania e política para a categoria;

- Combate as causas apontadas como motivadoras da ausência dos pescadores artesanais nas reuniões pertinentes aos interesses da categoria, e que resultaram no declínio da participação cidadã daqueles atores sociais;

- Redução da burocracia existente nas instituições públicas, que dificulta ou até impossibilita o exercício regular da atividade pesqueira, mediante a compilação das exigências legais, a simplificação dos atos de registro e a unificação dos sistemas informatizados; e,

- Inserção da Educação Ambiental política em todas as ações institucionais públicas, com a atuação do poder público no processo de resgate da cidadania ambiental dos pescadores artesanais, para reverter o atual quadro de descrédito, desconfiança e medo das instituições governamentais.

\begin{tabular}{l|c|c|c|c|c|c|} 
(C) Rev. Educ. Perspec. & Viçosa, $M G$ & v.9 & n.2 & p. 347-363 & maio/ago. 2018 & eISSN 2178-8359 \\
\hline
\end{tabular}


Essas medidas focam na importância da (re)construção da cidadania ambiental, base para a transformação socioambiental dos pescadores artesanais das cidades do Rio Grande/RS e de São José do Norte/RS, mediada para e pela Educação Ambiental política. Buscam, assim, um envolvimento ativo do ser humano com o meio ambiente natural, na construção de novos padrões de relações profissionais, desvinculados do controle estatal que impõe o medo, a humilhação e a desilusão aos pescadores.

Evidenciam, enfim, a necessidade da contribuição da Educação Ambiental para o empoderamento dos pescadores artesanais, incentivando uma participação ativa nas esferas de decisão de sua vida social e nos processos de gestão dos recursos pesqueiros no estuário da Lagoa dos Patos, numa verdadeira governança participativa, voltados para a conservação ambiental e edificação do bem coletivo.

\section{REFERÊNCIAS}

ADOMILLI, Gianpaolo Knoller. Trabalho, meio ambiente e conflito: um estudo antropológico sobre a construção da identidade social dos pescadores do Parque Nacional da Lagoa do Peixe - RS. 2002. 114 f. Dissertação (Mestrado em Antropologia Social). Universidade Federal do Rio Grande do Sul, Porto Alegre, RS, 2002.

ASMUS, Milton Lafourcade. A Planície Costeira e a Lagoa dos Patos. In: SEELIGER, Ulrich; ODEBRECHT, Clarisse; CASTELLO, Jorge Pablo (Org.). Os ecossistemas costeiro e marinho do extremo sul do Brasil. Rio Grande: Editora Ecoscientia, 1998. P. 9-12.

BERKES, Fikret et al. Gestão da pesca de pequena escala: diretrizes e métodos alternativos. In: KALIKOSKI, Daniela Coswig (Org.). Gestão da pesca de pequena escala: diretrizes e métodos alternativos. [Trad. de Ronaldo Costa]. Rio Grande (RS): FURG, 2006.

CAPORLINGUA, Vanessa Hernandez. A consciência ambiental dos juízes nas sentenças transformadoras. Jundiaí (SP): Paco Editorial, 2012.

CARVALHO, Isabel Cristina de Moura. Educação ambiental: a formação do sujeito ecológico. São Paulo: Cortez, 2011.

DIEGUES, Antônio Carlos. Pescadores, camponeses e trabalhadores do mar. Ensaios: 94. São Paulo: Ática, 1983.

DIEGUES, Antônio Carlos. Conhecimento tradicional e apropriação social do ambiente marinho. A pesca Construindo Sociedades. NUPAUB/CEMAR. São Paulo: Universidade de São Paulo, 2004. Disponível em: 〈http://tinyurl.com/ls25jkt〉. Acesso em: 03 fev. 2014.

DURKHEIM, Émile. Lições de sociologia: a Moral, o Direito e o Estado. São Paulo: T. A. Queiroz, 1983.

\begin{tabular}{l|c|c|c|c|c|c|} 
(C) Rev. Educ. Perspec. & Viçosa, $M G$ & v.9 & n.2 & p. 347-363 & maio/ago. 2018 & eISSN 2178-8359 \\
\hline
\end{tabular}


DURKHEIM, Émile. Sociologia e filosofia. Coleção Fundamentos de Direito. [Trad. de Fernando Dias Andrade]. São Paulo: Ícone, 2004.

DURKHEIM, Émile. As regras do método sociológico. São Paulo: Martins Fontes, 2007.

FÓRUM DA LAGOA DOS PATOS. Estatuto do Fórum da Lagoa dos Patos. Rio Grande (RS), 1998. Disponível em: 〈https://tinyurl.com/ydh3v8k7>. Acesso em: 23 abr. 2018.

FERRAZ JÚNIOR, Tércio Sampaio. Introdução ao estudo do direito. Técnica, Decisão e Dominação. São Paulo: Atlas, 2003.

GUSMÃO, Paulo Dourado de. Introdução ao estudo do direito. Rio de Janeiro: Forense, 2008.

HIGUSHI, Maria Inês Gasparetto; AZEVEDO, Genoveva Chagas de. Educação como processo na construção da cidadania ambiental. Revista Brasileira de Educação Ambiental, Brasília, v. 1, número zero, p. 63-70, 2004.

KALIKOSKI, Daniela Coswig. The Forum of the Patos Lagoon: An analysis of comanagement arrangement for conservation of coastal resources in southern Brazil. 2002. 257 f. Tese (Doctorate degree Program of Resource Management and Environmental Studies). University of British Columbia, Canadá, 2002.

KALIKOSKI, Daniela Coswig; VASCONCELLOS, Marcelo. Estudo de caso das condições técnicas, socioeconômicas e ambientais da pesca em escala reduzida no estuário da Lagoa dos Patos, Brasil. Uma metodologia para avaliação. FAO Fisheries and Aquaculture. Circular n. 1075. ROME, 2012.

LYRA FILHO, Roberto. Normas jurídicas e outras normas sociais. Revista Direito e Avesso, Brasília, n. 1, p. 49-60, 1982. Disponível em: <http://tinyurl.com/pgjkpqp>. Acesso em: 10 out. 2012.

MORAES, Roque; GALIAZZI, Maria do Carmo. Análise textual discursiva. Ijuí (RS): Unijuí, 2007.

MOURA, Gustavo Goulart Moreira. Guerra nos mares do Sul: a produção de uma monocultura marítima e os processos de resistência. 2013. $412 \mathrm{f}$. Tese (Doutorado em Ciência Ambiental). Universidade de São Paulo, São Paulo, 2013.

PEREIRA, Maria Odete da Rosa. Educação Ambiental com pescadores artesanais: um convite à participação. 2006. 170 f. Dissertação (Mestrado em Educação Ambiental). Universidade Federal do Rio Grande, Rio Grande (RS), 2006.

REIGOTA, Marcos. O que é educação ambiental. São Paulo: Brasiliense, 2009. 
REIS, Enir Girondi; VIEIRA, Pedro Castelli; STOTZ, Wolfgang (Org.). Manejo integrado do estuário da Lagoa dos Patos. Rio Grande: Ed. FURG, 2011.

VIEIRA, Liszt; BREDARIOL, Celso. Cidadania e política ambiental. Rio de Janeiro: Record, 1998.

\section{NOTAS}

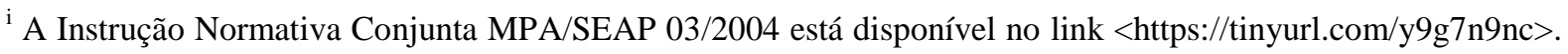
Acesso em: 23 abr. 2018.

ii Conforme a Política Nacional de Educação Ambiental - Lei 9.795/99, entende-se por Educação Ambiental os processos por meio dos quais o indivíduo e a coletividade constroem valores sociais, conhecimentos, habilidades, atitudes e competências voltadas para a conservação do meio ambiente, bem de uso comum do povo, essencial à sadia qualidade de vida e sua sustentabilidade.

iii Empoderamento seria o poder e a responsabilidade para fazer algo. A capacidade de uma pessoa ou grupo de pessoas de controlar ou participar das decisões que afetam a sua vida (BERKES et al., 2006).

iv A tradição refere-se às práticas tradicionais passadas, na maior parte dos casos, de geração em geração (ADOMILLI, 2002). O conhecimento tradicional diz respeito ao conjunto de práticas cognitivas e culturais, habilidades práticas e saber fazer transmitido oralmente nas comunidades de pescadores artesanais, com a função de assegurar a reprodução de seu modo de vida (DIEGUES, 2004), e que evolui por processos adaptativos (BERKES et al., 2006). Apesar de se tratarem de ideias complementares, a tradição e o conhecimento tradicional são apresentados separadamente neste trabalho, objetivando compreender as diversas origens morais evidenciadas pelos pescadores participantes.

\section{Sobre as Autoras}

1 Janaina Agostini Braido - Mestre em Educação Ambiental pela Universidade Federal do Rio Grande. E-mail: janabraido1@gmail.com - ORCID: http://orcid.org/0000-0003-2000-1951

2 Vanessa Hernandez Caporlingua - Doutora em Educação Ambiental pela Universidade Federal do Rio Grande. E-mail: vanessac@ vetorial.net - ORCID: http://orcid.org/0000-0002-8617-1892 